Case Report

\title{
Hypokalemic Paralysis due to Primary Sjögren Syndrome: Case Report and Review of the Literature
}

\author{
A. Garza-Alpirez, A. C. Arana-Guajardo, J. A. Esquivel-Valerio, \\ M. A. Villarreal-Alarcón, and D. A. Galarza-Delgado
}

Servicio de Reumatología, Departamento de Medicina Interna, Hospital Universitario "Dr. José Eleuterio González", Universidad Autónoma de Nuevo León, Monterrey, NL, Mexico

Correspondence should be addressed to A. C. Arana-Guajardo; ana.aranag@gmail.com

Received 29 March 2017; Revised 14 June 2017; Accepted 2 July 2017; Published 1 August 2017

Academic Editor: Syuichi Koarada

Copyright (c) 2017 A. Garza-Alpirez et al. This is an open access article distributed under the Creative Commons Attribution License, which permits unrestricted use, distribution, and reproduction in any medium, provided the original work is properly cited.

\begin{abstract}
Tubulointerstitial nephritis (TIN) is the main renal involvement associated with primary Sjögren syndrome (pSS). TIN can manifest as distal renal tubular acidosis (RTA), nephrogenic diabetes insipidus, proximal tubular dysfunction, and others. We present a 31-year-old female with hypokalemic paralysis due to distal RTA (dRTA). She received symptomatic treatment and hydroxychloroquine with a good response. There is insufficient information on whether to perform a kidney biopsy in these patients or not. The evidence suggests that there is an inflammatory background and therefore a potential serious affection to these patients, such as hypokalemic paralysis. We found 52 cases of hypokalemic paralysis due to dRTA in pSS patients. The majority of those patients were treated only with symptomatic medication. Patients who received corticosteroids had stable evolution even though they did not have another symptomatology. With such heterogeneous information, prospective studies are needed to assess the value of adding corticosteroids as a standardized treatment of this manifestation.
\end{abstract}

\section{Introduction}

Sjögren's syndrome is an autoimmune disease with glandular (salivary and lacrimal) and extraglandular (neurologic, renal, hepatic, respiratory, vascular, and cutaneous) manifestations. Tubulointerstitial nephritis (TIN) is the main renal involvement associated with primary Sjögren syndrome (pSS). TIN can manifest as distal renal tubular acidosis (RTA), nephrogenic diabetes insipidus, proximal tubular dysfunction, and others [1], of which RTA is the main clinical presentation [2]. RTA has been reported in 4.3 to $9 \%$ of pSS patients; it is more common in middle-aged women, and two-thirds of them will develop symptoms [2,3]. Hypokalemic paralysis is the initial symptom in seven percent of patients with Sjögren's syndrome [4]. We present a case of paralysis due to RTA in a pSS patient and also discuss the treatment in these patients.

\section{Case Report}

A 31-year-old female presented to the emergency room due to a 3-day history of progressive weakness and pain of the upper and lower extremities until walking was impossible. Two days before admission, cramps and generalized dysesthesias were evidenced. On admission, the patient presented mild dyspnea. Her past medical record was significant for polyarthralgias in carpal, metacarpophalangeal, and proximal interphalangeal joints and dry mouth for the past three months. She denied use of alcohol, illicit drugs, or herbal medicines. Her vital signs on admission were a temperature of $36.3^{\circ} \mathrm{C}$, a heart rate of 54 beats per minute, a respiratory rate of 20 breaths per minute, oxygen saturation of $97 \%$ at room air, capillary blood glucose of $103 \mathrm{~g} / \mathrm{dL}$, and blood pressure of $100 / 60 \mathrm{mmHg}$. On physical examination, the deep tendon reflexes were globally diminished, her muscle strength, both proximal and distal, was $3 / 5$ on Lovett's scale, and her tongue was dry and the infralingual salivary pooling was absent. Remarkable laboratory tests are shown in Table 1. A panoramic photo of minor salivary gland biopsy is shown in Figure 1. With all lab results, a distal RTA (dRTA) diagnosis due to pSS was made. Hypokalemia and metabolic acidosis were treated with intravenous potassium chloride and 
TABLE 1: Laboratory investigation.

\begin{tabular}{|c|c|}
\hline Laboratory investigation & Result \\
\hline $\mathrm{CBC}$ & Hemoglobin: $14.7 \mathrm{~g} / \mathrm{dL}$, WBC: $8.7 \times 10^{3}$, lymphocytes: $0.683 \times 10^{3}$, platelets: $159 \mathrm{~K} / \mu \mathrm{L}$ \\
\hline Serum electrolytes & Sodium: $138.2 \mathrm{mmol} / \mathrm{L}$, potassium: $2.7 \mathrm{mmol} / \mathrm{L}$, chloride: $101 \mathrm{mmol} / \mathrm{L}$ \\
\hline Serum chemistry & Glucose: $123 \mathrm{mg} / \mathrm{dL}$, creatinine: $0.8 \mathrm{mg} / \mathrm{dL}$, urea nitrogen: $13 \mathrm{mg} / \mathrm{dL}$ \\
\hline Liver panel & AST: $19 \mathrm{IU} / \mathrm{L}$, ALT: $13 \mathrm{IU} / \mathrm{L}$, albumin: $4.2 \mathrm{~g} / \mathrm{dL}$, total bilirubin: $0.7 \mathrm{mg} / \mathrm{dL}$ \\
\hline Urinalysis & pH: 8, leucocytes: 0-2/HPF, erythrocytes: 0/HPF, tubular cells: 0/HPF \\
\hline Urinary electrolytes & $\begin{array}{l}\text { Sodium: } 114 \mathrm{mmol} / \mathrm{L} \text {, potassium: } 32 \mathrm{mmol} / \mathrm{L} \text {, chloride: } 57.3 \mathrm{mmol} / \mathrm{L} \text {, creatinine: } \\
31.8 \mathrm{mg} / \mathrm{dL}\end{array}$ \\
\hline Urinary anion gap & $76 \mathrm{mmol} / \mathrm{L}$ \\
\hline Blood gas & $\mathrm{pH}: 7.12, \mathrm{HCO}_{3}: 11 \mathrm{mmol} / \mathrm{L}, \mathrm{pO}_{2}: 31 \mathrm{mmHg}, \mathrm{pCO}_{2}: 37 \mathrm{mmHg}$, saturation: $37 \%$ \\
\hline Serum anion gap & $10 \mathrm{mEq} / \mathrm{L}$ \\
\hline Thyroid panel & TSH: $2.06 \mu \mathrm{IU} / \mathrm{mL}$, free T4: $0.94 \mathrm{ng} / \mathrm{dL}$ \\
\hline Acute phase reactants & ESR: $31 \mathrm{~mm} / \mathrm{h}, \mathrm{CRP}<0.5 \mathrm{mg} / \mathrm{L}$ \\
\hline Virus panel & HIV-negative, $\mathrm{HBV}$-negative, $\mathrm{HCV}$-negative \\
\hline Rheumatoid factor & IgM: 155.7 IU/mL, IgG: 6.7 IU/mL, IgA: $12.2 \mathrm{IU} / \mathrm{mL}$ \\
\hline ANAs by IFA & $1: 5120$ fine speckled \\
\hline SSA/SSB by ELISA & 200.14/19.67 IU/mL \\
\hline $\begin{array}{l}\text { Unstimulated whole saliva flow, without } \\
\text { anesthesia }\end{array}$ & $1.4 \mathrm{~mL} / 15$ minutes \\
\hline Minor salivary gland biopsy* & Positive, focus score of 5 \\
\hline Schirmer's test & Right eye: $7 \mathrm{~mm}$, left eye: $10 \mathrm{~mm}$ \\
\hline
\end{tabular}

${ }^{*}$ According to [5].

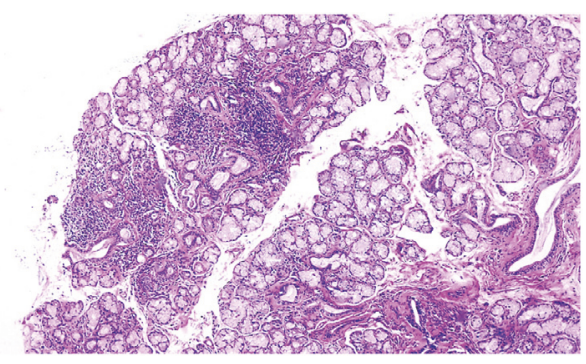

Figure 1: A panoramic photo of minor salivary gland biopsy. A chronic lymphocyte focal sialadenitis was observed.

sodium bicarbonate. Then, we initiated hydroxychloroquine. The patient was discharged and we followed her up in our clinic every two months for the next eight months. She was reported to be asymptomatic with the use of potassium citrate only.

\section{Discussion}

A recent set of classification criteria for $\mathrm{pSS}$ were published by the ACR/EULAR in 2016 [6] and this applies to the individual that has a score of $\geq 4$. According to this, the diagnosis of this autoimmune disease was made in our patient (labial salivary gland with a focus score of $\geq 1$, anti-SSA positive, and an unstimulated whole saliva flow of less than $0.1 \mathrm{~mL} / \mathrm{min}$ ). Renal involvement in pSS is the result of two distinct pathophysiological processes: TIN and glomerulopathy [1]. The tubulointerstitial inflammation is the most common renal lesion described by Talal et al. [7]. dRTA prevalence fluctuates between 5 and $70 \%$, according to population studies $[4,8,9]$. dRTA can be classified as complete or incomplete; the former is characterized by metabolic acidosis with morning urine $\mathrm{pH}$ $>5.5$ and a positive urinary anion gap. The incomplete form presents with normal serum bicarbonate levels but urinary $\mathrm{pH}$ fails to fall to $<5.3$ after ammonium chloride loading [10]. The pathogenic mechanism of this complication is not completely understood. Antibodies to vacuolar H+-ATPase and anion exchanger 1 , as well as antibodies to carbonic anhydrase II, have been implicated in the pathogenesis [11-13]. Another hypothesis is a defective S-phase-kinaseassociated protein-1, a component of the regulator of the ATPase of vacuolar and endosomal membranes that could induce a defective V-ATPase assembly [14]. Also, a possible relation between antibodies anti-SSA/Ro and dRTA has been described as one pathogenic mechanism of development [15].

Hypokalemia is the most common electrolyte abnormality in patients with dRTA. The causes of hypokalemia include decreased distal tubular $\mathrm{Na}$ delivery, secondary hyperaldosteronism, defective H-KATPase, and bicarbonaturia [16]. Hypokalemic paralysis may precede sicca syndrome from three months to four years in patients with a final diagnosis of pSS $[17,18]$.

Renal biopsy is not mandatory in these patients [2], but it may help us evidence the inflammatory mechanisms that trigger the disease. As has been demonstrated by Evans et al. in twelve patients with TIN secondary to pSS, they observed CD4+ T-cell predominance in biopsies, similar to those seen 


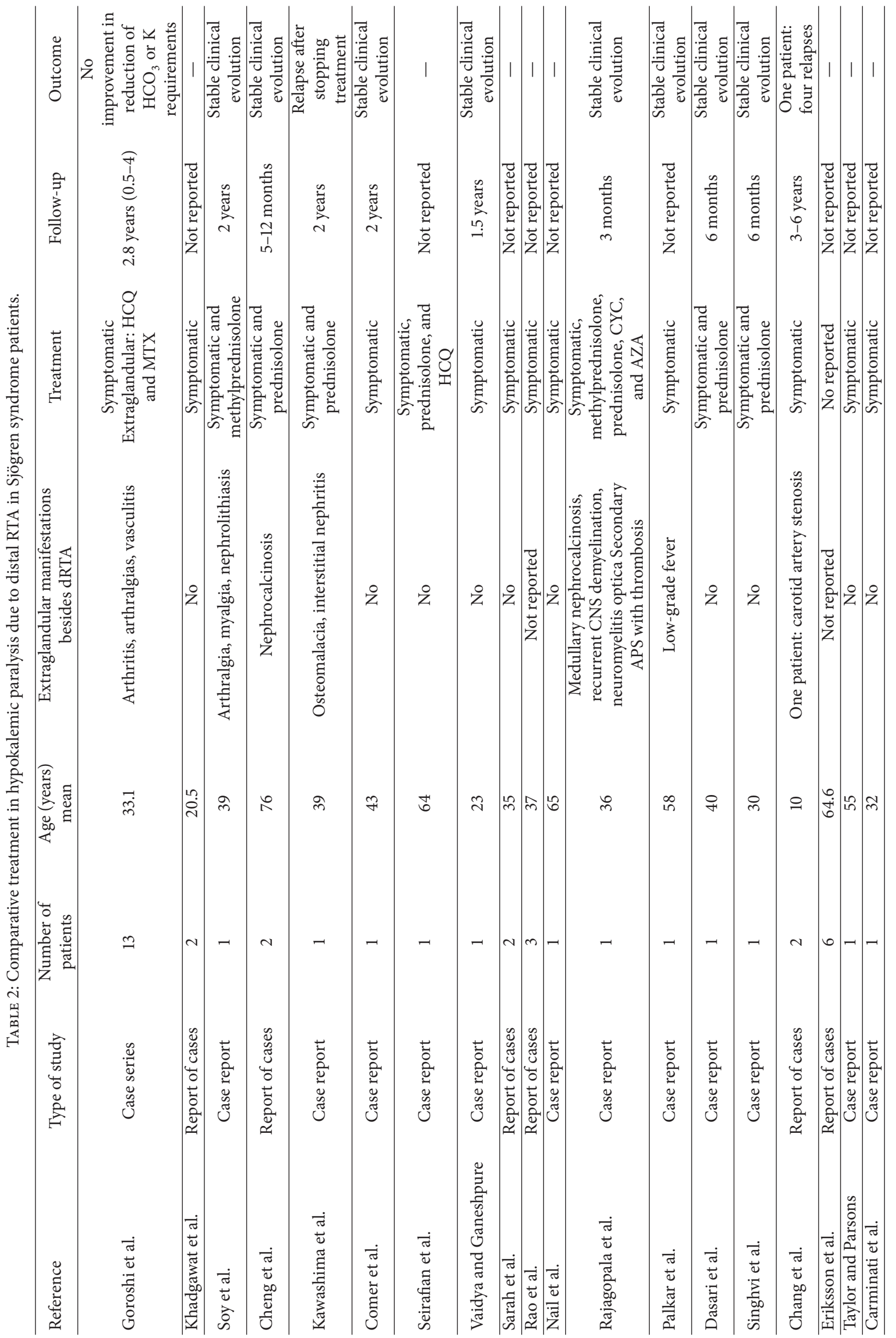




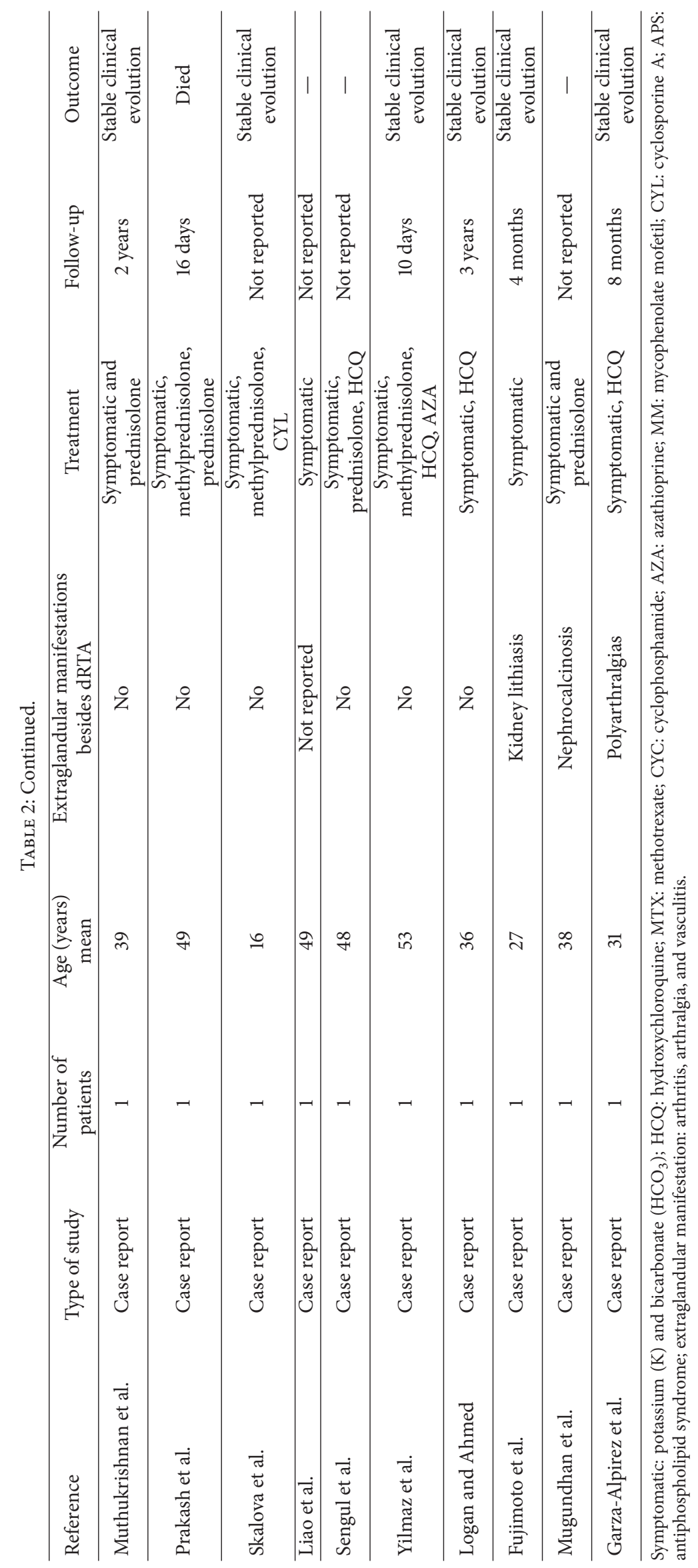


in lip salivary glands [19]. Also, similar lymphocytic infiltrates around renal tubules have been observed [20]. More data from prospective studies of pSS biopsies are needed in order to enhance knowledge in these subsets of patients and also to determine the best treatment.

dRTA treatment includes potassium restitution before alkali therapy, because the last might aggravate hypokalemia by enhancing the shift of potassium into cells and bicarbonaturia [21]. In the beginning, hydroxychloroquine was started in the suspicion of a secondary cause of Sjögren's syndrome but it was later discontinued.

RTA is not a usual indication for immunomodulatory therapy in pSS, even though it is an extraglandular manifestation [22]. Steroid therapy in cases that are nonresponsive to replacement therapy and in those with recurring hypokalemic paralysis attacks is indicated [23].

We searched in MEDLINE, IMBIOMED, and Google Scholar for clinical cases of hypokalemic paralysis due to pSS. We included only articles written in English or Spanish. In Table 2, we describe each one of them: number of cases, age of patients, extraglandular manifestations besides dRTA, treatment, and outcome. We found fifty-two cases for analysis but we included only cases with a complete report of treatment $[15,21-47]$. We observed the highest frequency of this clinical presentation in young adults of the female gender. It is important to note that, in some cases, dRTA was present before the diagnosis of pSS. All patients received symptomatic treatment. We noted that 25\% (13/52) received corticosteroids. Of these patients, $61 \%(8 / 13)$ did not report extraglandular manifestations, besides dRTA. The outcomes (at different duration) were clinically stable in 61\% (8/13), 8\% $(1 / 13)$ had a relapse after treatment was stopped, $8 \%(1 / 13)$ died from an infectious cause, and 23\% (3/13) did not report the outcome.

On the other hand, $32.6 \%$ (17/52) received only symptomatic treatment. Of these patients, $41 \%$ (7/17) did not report extraglandular manifestations. Only in six (35\%) patients was the outcome reported, of whom $83 \%(5 / 6)$ were clinically stable, and in $17 \%$ (1/6) four relapses occurred.

In the early diagnosis era of autoimmune diseases (like in rheumatoid arthritis), the importance of recognizing kidney involvement before glandular symptoms appear has been observed previously $[21,25,28]$. Also, we consider it important to determine whether some factors can trigger the beginning of this manifestation. This association has been observed by Logan and Ahmed. They described in a patient the use of Echinacea as a trigger of pSS [45]. Perhaps this means that the immunological tolerance is already lost, and some infections or substances can precipitate the clinical disease. We agree with the recommendation given by François and Mariette to screen all pSS patients according to manifestations every six to twelve months [10].

With such heterogeneous information, prospective studies are needed to assess the value of adding corticosteroids as a standardized treatment of this manifestation. We may consider that, in cases of hypokalemic paralysis in which there is a potentially life-threatening presentation, the treatment with corticosteroids could be justified.

\section{Conflicts of Interest}

The authors declare that there are no conflicts of interest regarding the publication of this article.

\section{References}

[1] R. Evans, A. Zdebik, C. Ciurtin, and S. B. Walsh, "Renal involvement in primary Sjögren's syndrome," Rheumatology, vol. 54, no. 9, pp. 1541-1548, 2015.

[2] M. Ramos-Casals, P. Brito-Zerón, R. Seror et al., "Characterization of systemic disease in primary Sjögren's syndrome: EULAR-SS Task Force recommendations for articular, cutaneous, pulmonary and renal involvements," Rheumatology, vol. 54, no. 12, pp. 2230-2238, 2015.

[3] M. Ramos-Casals, P. Brito-Zerón, R. Solans et al., "Systemic involvement in primary Sjögren's syndrome evaluated by the EULAR-SS disease activity index: Analysis of 921 spanish patients (GEAS-SS registry)," Rheumatology (United Kingdom), vol. 53, no. 2, Article ID ket349, pp. 321-331, 2014.

[4] H. Ren, W. M. Wang, X. N. Chen, W. Zhang, X. L. Pan Wang et al., "Renal involvement and followup of 130 patients with primary Sjögren's syndrome," The Journal of Rheumatology, vol. 35, pp. 278-284, 2008.

[5] D. M. Chisholm and D. K. Mason, "Labial salivary gland biopsy in Sjögren's disease," Journal of Clinical Pathology, vol. 21, no. 5, pp. 656-660, 1968.

[6] C. H. Shiboski, S. C. Shiboski, R. Seror et al., "2016 American College of Rheumatology/European League Against Rheumatism classification criteria for primary Sjogren's syndrome A consensus and data-driven methodology involving three international patient cohorts," Annals of the Rheumatic Diseases, vol. 76, no. 1, pp. 9-16, 2016.

[7] N. Talal, E. Zisman, and P. H. Schur, "Renal tubular acidosis, glomerulonephritis and immunologic factors in Sjogren's syndrome," Arthritis and Rheumatology, vol. 11, no. 6, pp. 774-786, 1968.

[8] S. Maripuri, J. P. Grande, T. G. Osborn et al., "Renal involvement in primary sjögren's syndrome: a clinicopathologic study," Clinical Journal of the American Society of Nephrology, vol. 4, no. 9, pp. 1423-1431, 2009.

[9] N. Bossini, S. Savoldi, F. Franceschini et al., "Clinical and morphological features of kidney involvement in primary Sjögren's syndrome," Nephrology Dialysis Transplantation, vol. 16, no. 12, pp. 2328-2336, 2001.

[10] H. François and X. Mariette, "Renal involvement in primary Sjögren syndrome," Nature Reviews Nephrology, vol. 12, no. 2, pp. 82-93, 2016.

[11] B. Bastani, L. Haragsim, S. Gluck, and K. C. Siamopoulos, "Lack of h-atpase in distal nephron causing hypokalaemic distal rta in a patient with sjögren's syndrome," Nephrology Dialysis Transplantation, vol. 10, no. 6, pp. 908-909, 1995.

[12] F. Takemoto, J. Hoshino, N. Sawa et al., "Autoantibodies against carbonic anhydrase II are increased in renal tubular acidosis associated with Sjögren syndrome," American Journal of Medicine, vol. 118, no. 2, pp. 181-184, 2005.

[13] P. E. DeFranco, L. Haragsim, P. G. Schmitz, B. Bastani, and J. P. Li, "Absence of vacuolar H+-ATPase pump in the collecting duct of a patient with hypokalemic distal renal tubular acidosis and Sjögren's syndrome," Journal of the American Society of Nephrology, vol. 6, no. 2, pp. 295-301, 1995. 
[14] P. Sandhya and D. Danda, "Role of vacuolar ATPase and Skp1 in Sjögren's syndrome," Medical Hypotheses, vol. 82, no. 3, pp. 319-325, 2014.

[15] P. Eriksson, T. Denneberg, S. Eneström, B. Johansson, F. Lindström, and T. Skogh, "Urolithiasis and distal renal tubular acidosis preceding primary Sjögren's syndrome: A retrospective study 5-53 years after the presentation of urolithiasis," Journal of Internal Medicine, vol. 239, no. 6, pp. 483-488, 1996.

[16] S.-H. Lin, S. Cheema-Dhadli, M. Gowrishankar, E. B. Marliss, K. S. Kamel, and M. L. Halperin, "Control of excretion of potassium: lessons from studies during prolonged total fasting in human subjects," American Journal of Physiology-Renal Physiology, vol. 273, no. 5, pp. F796-F800, 1997.

[17] R. Shioji, T. Furuyama, S. Onodera, H. Saito, H. Ito, and Y. Sasaki, "Sjögren's syndrome and renal tubular acidosis," The American Journal of Medicine, vol. 48, no. 4, pp. 456-463, 1970.

[18] K.-K. Pun, C.-K. Wong, E. Y.-L. Tsui, S. C.-F. Tam, A. W.-C. Kung, and C. C.-L. Wang, "Hypokalemic periodic paralysis due to the Sjogren syndrome in Chinese patients," Annals of Internal Medicine, vol. 110, no. 5, pp. 405-406, 1989.

[19] R. D. R. Evans, C. M. Laing, C. Ciurtin, and S. B. Walsh, "Tubulointerstitial nephritis in primary Sjögren syndrome: clinical manifestations and response to treatment," BMC Musculoskeletal Disorders, vol. 5, no. 17, p. 2, 2016.

[20] N. Talal, "Sjögren's syndrome, lymphoproliferation, and renal tubular acidosis," Annals of Internal Medicine, vol. 74, no. 4, pp. 633-634, 1971.

[21] C.-J. Cheng, J.-S. Chiu, C.-C. Chen, and S.-H. Lin, "Unusual cause of hypokalemic paralysis in aged men: Sjögren syndrome," Southern Medical Journal, vol. 98, no. 12, pp. 1212-1215, 2005.

[22] M. Goroshi, S. Khare, T. Jamale, and N. Shah, "Primary Sjogren's syndrome presenting as hypokalemic paralysis: a case series," Journal of Postgraduate Medicine, vol. 63, no. 2, p. 128, 2016.

[23] M. Soy, Ö. N. Pamuk, M. Gerenli, and Y. Çelik, "A primary Sjögren's syndrome patient with distal renal tubular acidosis, who presented with symptoms of hypokalemic periodic paralysis: report of a case study and review of the literature," Rheumatology International, vol. 26, no. 1, pp. 86-89, 2005.

[24] R. Khadgawat, N. Tandon, D. Khandelwal, S. Bhattacharya, S. Kaur, and A. Ammini, "Hypokalemic paralysis as a presenting manifestation of primary Sjögren/s syndrome: a report of two cases," Indian Journal of Endocrinology and Metabolism, vol. 16, no. 5, pp. 853-855, 2012.

[25] M. Kawashima, T. Amano, Y. Morita, M. Yamamura, and H. Makino, "Hypokalemic paralysis and osteomalacia secondary to renal tubular acidosis in a case with primary Sjögren's syndrome," Modern Rheumatology, vol. 16, no. 1, pp. 48-51, 2006.

[26] D. M. Comer, A. G. Droogan, I. S. Young, and A. P. Maxwell, "Hypokalaemic paralysis precipitated by distal renal tubular acidosis secondary to Sjögren's syndrome," Annals of Clinical Biochemistry, vol. 45, no. 2, pp. 221-225, 2008.

[27] S. Seirafian, M. Shafie, A. Abedini, B. Pakzad, and P. Roomizadeh, "Recurrent attacks of hypokalemic quadriparesis: an unusual presentation of primary Sjögren syndrome," Internal Medicine, vol. 55, no. 13, pp. 1797-1800, 2016.

[28] G. Vaidya and S. Ganeshpure, "Sjogren's syndrome with distal renal tubular acidosis presenting as hypokalaemic paralysis," BMJ Case Reports, vol. 19, 2012.

[29] S. Sarah, G. Lijo, E. Sukanya, and D. Rajasekaran, "Renal tubular acidosis due to Sjogren's syndrome presenting as hypokalemic quadriparesis: a report of two cases," Indian Journal of Nephrology, vol. 25, no. 6, pp. 386-387, 2015.

[30] N. Rao, M. John, N. Thomas, S. Rajaratnam, and M. S. Seshadri, "Aetiological, clinical and metabolic profile of hypokalaemic periodic paralysis in adults: a single-centre experience," National Medical Journal of India, vol. 19, no. 5, pp. 246249, 2006.

[31] M. Nail, T. Bhat, M. Naqash et al., "Hypokalemic quadriparesis in an elderly female," Indian Journal of Nephrology, vol. 22, no. 5, pp. 402-403, 2012.

[32] S. Rajagopala, G. Danigeti, and D. Subrahmanyan, "An unusually dry story," Indian Journal of Critical Care Medicine, vol. 19, no. 9, pp. 550-553, 2015.

[33] A. V. Palkar, S. Pillai, and G. C. Rajadhyaksha, "Hypokalemic quadriparesis in Sjogren syndrome," Indian Journal of Nephrology, vol. 21, no. 3, pp. 191-193, 2011.

[34] S. Dasari, K. Naha, G. Vivek, V. Acharya, and M. Hande, "Primary presentation with acute flaccid quadriparesis in Sjogren's syndrome sans sicca," BMJ Case Reports, vol. 2013, 2013.

[35] J. Singhvi, A. Ganguli, and B. Kaur, "Primary Sjogren's syndrome presenting as Acute Flaccid Quadriplegia," Annals of Neurosciences, vol. 17, no. 2, 2010.

[36] Y.-C. Chang, C.-C. Huang, Y.-Y. Chiou, and C.-Y. Yu, "Retal tubular acidosis complicated with hypokalemic periodic paralysis," Pediatric Neurology, vol. 13, no. 1, pp. 52-54, 1995.

[37] I. Taylor and M. Parsons, "Hypokalemic paralysis revealing Sjögren's syndrome," Journal of Clinical Neuroscience, vol. 11, no. 3, pp. 319-321, 2004.

[38] G. Carminati, A. Chena, J. M. Orlando, S. Russo, S. Salomón, and J. A. Carena, "Distal renal tubular acidosis with rhabdomyolysis as the presenting form in 4 pregnant women," Nefrologia, vol. 21, no. 2, pp. 204-208, 2001.

[39] J. Muthukrishnan, S. Dawra, V. Marwaha, and C. S. Narayanan, "Sjögren's syndrome presenting as hypokalemic paralysis," Medical Journal Armed Forces India, vol. 71, pp. S172-S174, 2015.

[40] E. B. S. Prakash, M. E. Fernando, M. Sathiyasekaran, R. M. Bhoopathy, J. J. Jayanth, and J. Samuel, "Primary Sjögren's syndrome presenting with distal renal tubular acidosis and rhabdomyolysis," Journal of Association of Physicians of India, vol. 54, pp. 949-950, 2006.

[41] S. Skalova, L. Minxova, and R. Slezak, "Hypokalaemic paralysis revealing Sjogren's syndrome in a 16-year old girl," Ghana Medical Journal, vol. 42, pp. 124-128, 2008.

[42] C.-Y. Liao, C.-C. Wang, I.-H. Chen, J.-C. Shiang, M.-Y. Liu, and M.-K. Tsai, "Hypokalemic paralysis as a presenting manifestation of primary Sjögren's syndrome accompanied by vitamin D deficiency," Internal Medicine, vol. 52, no. 20, pp. 2351-2353, 2013.

[43] E. Sengul, F. Bunul, A. Yazici et al., "An unusual initial presentation of Sjögren's syndrome: severe hypokalemic paralysis secondary to distal renal tubular acidosis," Eurasian Journal of Medicine, vol. 45, no. 3, pp. 218-221, 2013.

[44] H. Yilmaz, M. Kaya, M. Özbek, K. Üreten, and S. I. Safa Yildirim, "Hypokalemic periodic paralysis in Sjogren's syndrome secondary to distal renal tubular acidosis," Rheumatology International, vol. 33, no. 7, pp. 1879-1882, 2013.

[45] J. L. Logan and J. Ahmed, "Critical hypokalemic renal tubular acidosis due to Sjögren's syndrome: association with the purported immune stimulant echinacea," Clinical Rheumatology, vol. 22, no. 2, pp. 158-159, 2003. 
[46] T. Fujimoto, H. Shiiki, Y. Takahi, and K. Dohi, "Primary Sjögren's syndrome presenting as hypokalaemic periodic paralysis and respiratory arrest," Clinical Rheumatology, vol. 20, no. 5, pp. 365-368, 2001.

[47] K. Mugundhan, M. C. Mayan Vasif, P. D. Nidhin et al., "Hypokalemic paralysis in Sjogren's syndrome secondary to renal tubular acidosis," Journal of Association of Physicians of India, vol. 64, p. 72, 2016. 


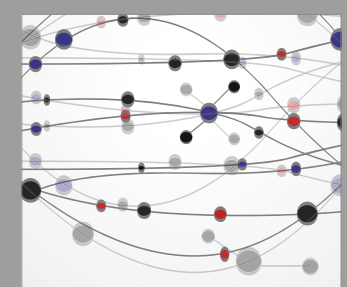

The Scientific World Journal
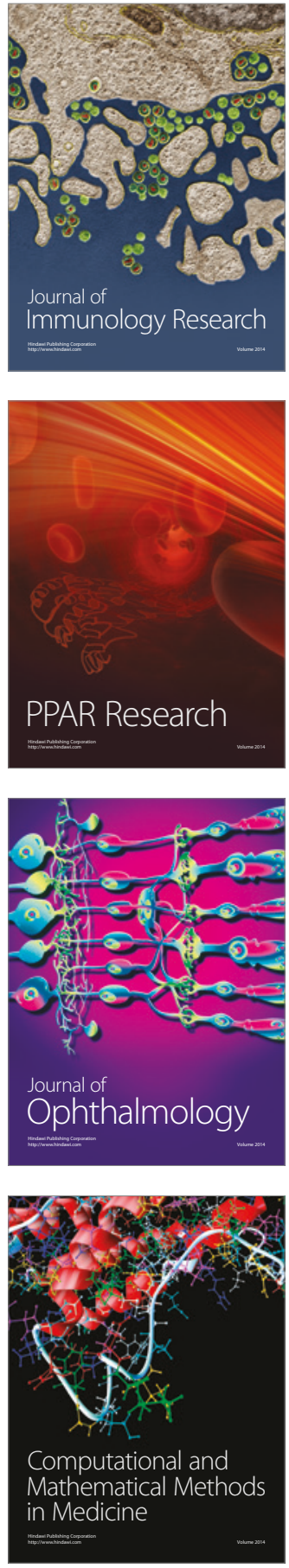

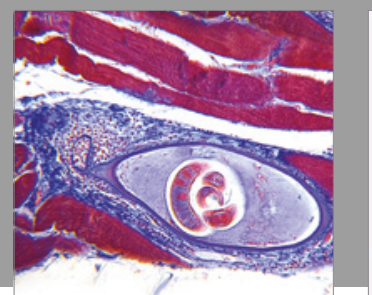

Gastroenterology Research and Practice
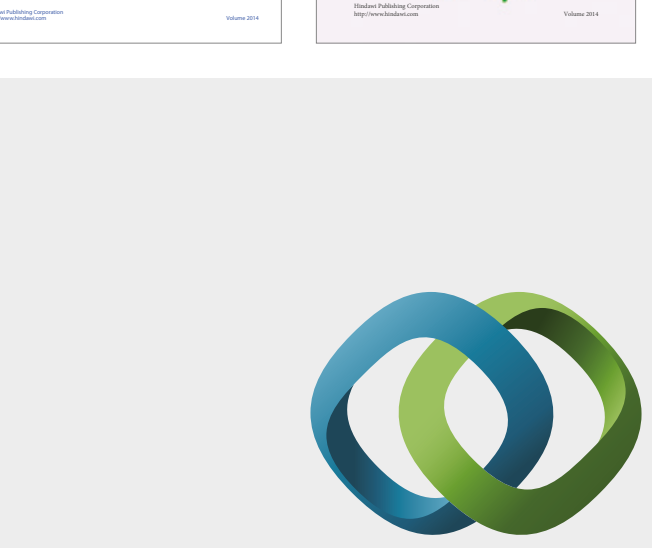

\section{Hindawi}

Submit your manuscripts at

https://www.hindawi.com
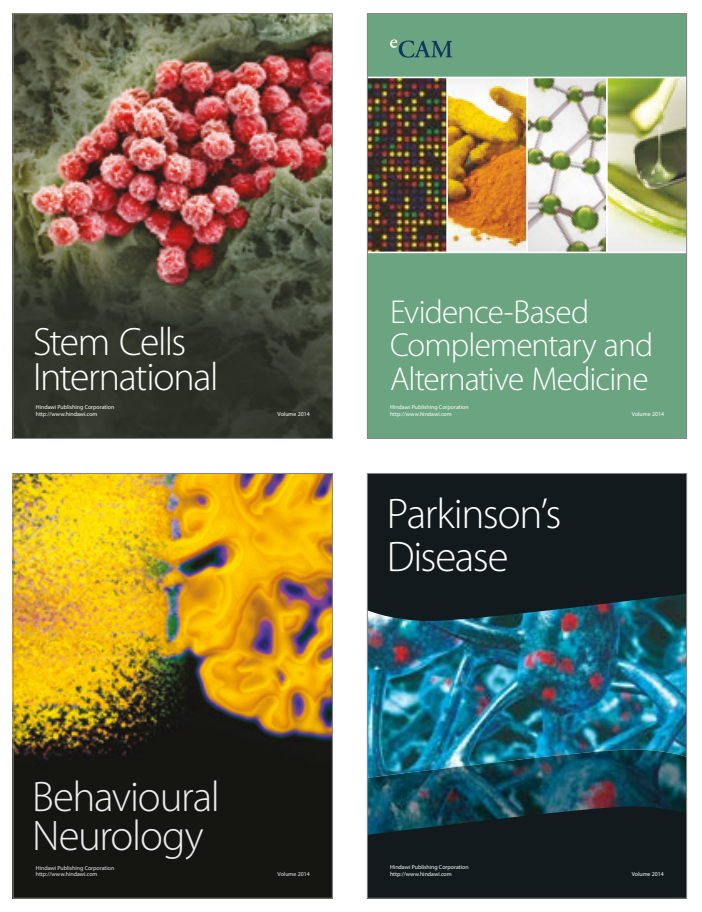
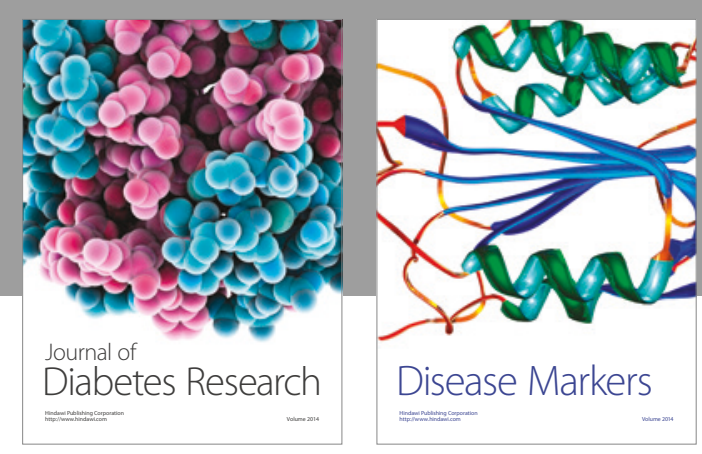

Disease Markers
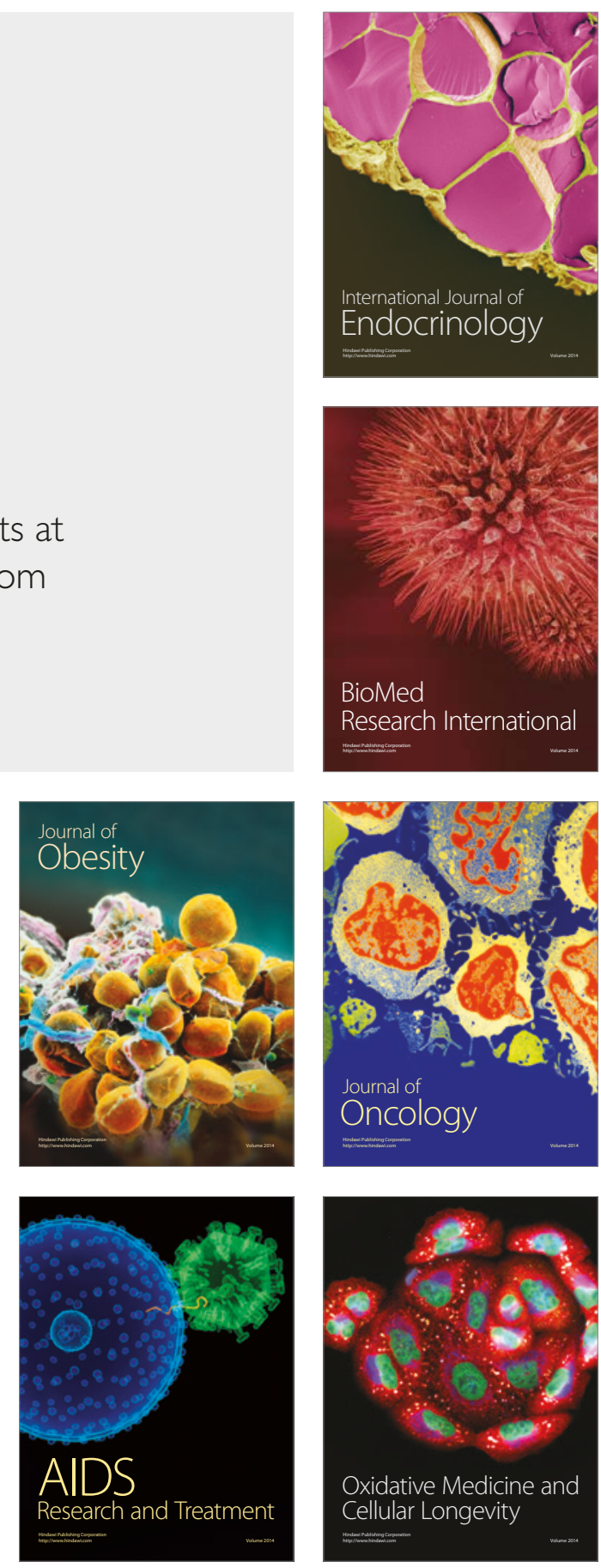